\title{
OBSERVATIONS OF THE 1989 LOMA PRIETA EARTHQUAKE
}

\section{Peter Marks *}

\section{INTRODUCTION}

Ths report has been modified from one presented to the wellington city council and sets out observations and conclusions gained from a visit to San Francisco and the area affected by the Loma Prieta Earthquake which struck the San Francisco Bay area on 17 october 1989. I visited the area from 29 November to 8 December 1989.

The earthquake occurred at $5.04 \mathrm{pm}$ local time and was measured at 7.1 on the Richter scale. It was located $16 \mathrm{~km} \mathrm{NE}$ of Santa Cruz and $30 \mathrm{~km}$ south of San Jose in the santa cruz mountains, $100 \mathrm{~km}$ south of San Francisco city. Sixty two people were killed, 994 homes destroyed with 18,000 not occupiable immediately after the earthquake. 155 businesses were destroyed and 2,500 businesses closed temporarily. cost of damage is estimated at between 6.5 and 10 billion US dollars. San Francisco city suffered a major visitor decline after the earthquake.

I attended as one of three members of the New Zealand National society for Earthquake Engineering "Follow Up" Reconnaissance team for the purpose of establishing what damage had occurred to sewer and stormwater systems, water supply systems and gas utilities. My visit was funded by the wellington city Council and was mostly devoted to study of sewer and stormwater systems.

\section{GENERAL OBSERVATIONS}

The main area where it is known that damage to sewer and stormwater systems has occurred was in the Marina district, an area which includes about 20 hectares of reclamation fill on the northern side of San Francisco city. Liquefaction and soil amplification of the fill material caused considerable damage to buildings in the area and water, sewer/stormwater and gas services were severely damaged. Since the earthquake all gas services have been relaid at a cost of about \$2OM, over 72 significant water main breaks have been repaired and numerous service connections and minor breaks needed repair. About $15 \%$ of the sewer/stormwater in the Marina area requires replacement.

Outside of the Marina District damage to gas and water mains was sporadic except close to

* Director, Drainage Division, Wellington city Council the epicentre. The extent of damage to sewer and stormwater pipe systems has still not really been assessed as the priorities have been on restoring other services and dealing with the more obvious impacts of the earthquake. Similarities between parts of downtown San Francisco and the Marina area to Wellington were a useful reminder of what could happen in Wellington.

This earthquake was not large by many standards but it reinforced a number of things that people involved with earthquakes and earthquake preparedness have been saying for some time, ie

1. Modern, well designed structures will survive.

2. Older structures and reinforced masonry are vulnerable.

3. Structures on poor soils will be subject to greater forces than structures on solid ground.

4. Search and rescue capibilities locally need to be expanded. Local communities are very much on their own for the first 24 hours.

5. Preparedness works.

In addition, it seems to have been the first significant earthquake in an English speaking developed country for almost two decades. It is therefore valuable in its applicability to the New Zealand scene.

The epicentre was in a mountain region, not disimilar to many hilly areas of New Zealand. Many landslides and slumping of filled areas occurred. The observation was made that many areas which may be subject to slipping in heavy rain were the areas that suffered landslip during the earthquake.

\section{IMPACT UPON OTILITIES}

Many instances of damage to pipelines occurred. Failures of all types, fracture, shear, lateral displacement, pulling apart and shearing at connections occurred. Many failures occurred at planes of weakness such as places where corrosion had started, cracking may already have commenced, or the junction of a large pipe and a smaller one.

The loss of power was a major impact upon sewer and water systems. Many areas were without power for up to two days this 
affecting water supply, treatment plant operation and communication systems.

The effect of poor soils led to wide spread damage to water and gas services with the full extent of damage to sewers and stormwater yet to be properly assessed as being buried they are much more difficult to inspect. Water and sewage treatment plants generally suffered little damage with one exception being the Rinconada Water Treatment plant which suffered severe damage as a result of wave action.

Rather than repeat instances of damage, which are very well documented in an American Society of Civil Engineers reconnaisance group report on the Earthquake, their summary of conclusions on the performance of water and sewage life lines has been included in the Appendix.

\section{PREPAREDNES8}

This earthquake has served as a reminder that a major earthquake of at least similar intensity to that which struck San Francisco has a reasonable possibility of striking Wellington over the next few decades and this has been reinforced by recent moderate earthquakes in $\mathrm{NZ}$. Local Authorities must take steps to limit the impact upon the very valuable infrastructure that they own and prepare to deal with the resultant damage.

From my visit to San Francisco I have gained the impression that emergency services and the civil defence type organisations coped well with the emergency. It must be remembered that in the U.S. the police are part of the Local Authority structure. Most of the Californian preparedness appeared to be directed towards personal, political and civil defence type responses. This ensured that most people knew what to do. However, I saw no sewage authority that had a detailed plan of what to do at worker level. It is my understanding that staff came in to their depots and the management directed activities as it believed necessary. Most of my studies were into reaction by sewage authorities and these generally had few problems compared with those encountered by water authorities (and gas in the Marina Area).

A significant lesson guoted by officials in California was that preparedness had worked and one aspect of preparedness that had been undertaken by a number of authorities had been in the area of assessment of their facilities for vulnerability to earthquakes.

Part of a vulnerability assessment involves identifying hazardous areas within the work environment. The fixing of cabinets, shelving and other furniture so that it does not fall on people in an earthquake is one important facet. In San Francisco they were fortunate that the earthquake occurred after many people had finished work otherwise injuries and death from falling objects could have been a lot higher. As well as preventing furniture falling on people attention should also be paid to preventing expensive computer and other valuable equipment from falling off desks etc. I saw one instance of a $\$ 50,000$ laboratory apparatus that had slid along a bench almost to the point of crashing but had been restrained only by the power cord.

An observation from Santa Cruz was that once it had been established that apparent damage to sewage facilities had been limited the drainage system personnel were diverted to more pressing problems.

\section{CONCLUSION}

The Loma Prieta earthquake was a large earthquake but not a big one. San Francisco was $100 \mathrm{~km}$ from the epicentre and outside the three major catastrophes reported suffered mostly minor damage. However, it served as a very timely reminder that earthquakes are a reality for communities such as Wellington, and we should be taking our preparedness more seriously.

The visit put the impact of the earthquake into some perspective and gave me a lot of detail that I would not have got out of reports. It also brought home the reality of earthquakes which has equipped me to better campaign for better preparing my employer, for the day Wellington City has to react.

\section{APPENDIX}

\section{LOMA PRIETA EARTHQUAKE}

\section{CONCLUSIONS AND RECOMMENDATIONS}

The biggest impact of the Loma Prieta earthquake $(M=7.1)$ at 5:04 P.M. on October 17,1989 on water and sewage lifelines was the loss of power, especially from a few hours to several days. The survivorability of the public power supply is questionable in a emergency like an earthquake; therefore, the U.S. Environmental Protection Agency (FPA) requires either a dual power supply or an emergency supply on their newly funded treatment plants. There are more water and sewage systems within the area impacted by the earthquake than could be contacted in the time permitted. A complete survey is left to future researchers. Also, it was not possible to put all information available in this report; therefore, these details are left to future researchers for study.

Based on this preliminary reconnaissance survey, the earthquake has reiniorced the lessons learned in previous earthquakes that water and sewage lifelines should:

1. Provide permanent emergency power or alternative engine-driven equipment when there is a loss of power for critical operating and treatment facilities.

Portable generators are suitable for water booster pumping, sewer force main pumping, chlorinators and treatment equipment; however, they may not always be available or may be limited in capacity or number, and it often takes a substantial amount of time to 
transport them to the needed locations and connect them to vital equipment.

2. Provide permanent emergency power to the critical support facilities.

Examples of critical support facilities are electrically operated refueling pumps and water quality laboratory equipment. Repair trucks and construction equipment require fuel and the refueling pumps are all electrically operated. The fuel pumps need to be connected to the emergency power or at least have quick connects for a portable generator. Water quality laboratory equipment is necessary to test the potability of a potentially polluted water system.

3. Conduct regular periodic tests of emergency power or engine driven equipment under load.

Normally this equipment is tested weekly or monthly without load; however, some systems react differently under load. This test should be performed at least every six to 12 months after careful analyses of critical facilities that may be impacted by a sudden opening of the main circuit breaker to shut down the power supply.

4. Maintain portable light plants, generators, chlorinators and pumps.

Portable light plants are necessary for night time repair work. Portable generators can be used to operate portable pumps to dewater construction sites or to operate portable chlorinators to disinfect repaired water mains.

5. Develop a separate radio communication system, independent of the telephone system.

Following this earthquake, as is typical after other earthquakes the telephone system was blocked by a high volume of calls. Regional or city emergency radio communication systems give priority to fire, police and medical emergencies. A separate water or sewage radio frequency system for dispatching repair crews and equipment is desirable. A base station, alternate base station, emergency power supply and mobile units should be a part of this system.

6. Maintain an inventory of repair materials, parts and fuel.

There was no reported shortage for the medium to larger agencies; however, some agencies reported their supplies were almost depleted of specific items. Some small agencies had essentially no inventory and had to order and wait for, if not readily available, needed repair material.

7. Improve the statewide mutual aid program.

In California, under the state office of Emergency Services (OES) there is a Utilities Division to coordinate the water, gas and electrical mutual aid program. Each activity is administered by a designated representative from a major utility as the state operating engineer to coordinate the mutual aid program. Although volunteer mutual aid did occur for this earthquake, there needs to be a review of the organization and the testing of the communication system for the OES Utilities Division program.

8. Establish guidelines for statewide emergency water quality sampling and public notification guidelines.

Small and medium agencies who rely on outside water quality laboratories and have no public relations staff need some uniform guidelines as to what minimum testing is required to be sure of a potable water supply in an emergency. Also, sample news releases should be made available to inform the public of what they should do (that is,boil water) in the case of a potentially contaminated water supply. These messages could be used by the local radio and television stations.

9. Conduct an earthquake vulnerability assessment of water and sewage lifelines facilities.

Every agency should have an earthquake vulnerability assessment made of its system. This may be done by consultants or in-house engineering or technical personnel. These people need to be trained as to what things to look for in evaluating the facilities. They should identify:

(a) Simple and low cost mitigation measures, such as anchorage of equipment, chemical or compressed gas tanks, supply cabinets and warehouse storage facilities.

(b) Medium cost mitigation, such as, emergency power supply, roof to wall connection or wall to footing connections for buildings that house pumps or treatDlent equipment.

(c) Facilities that require more detailed engineering analysis, such as, large tanks, large buildings and treatment plants. The detailed analysis could require demolition and complete reconstruction of the facility, resulting in a high cost mitigation measure.

\section{Develop emergency response plan.}

Agencies should have a simple emergency response plan, even though many agencies operate on a 24-hour emergency response basis for their normal operation. The plan should include, but not limited to emergency reporting procedures, reporting locations, alternative assigned duties, training, provision for providing meals to field locations, plan for inspection of critical facilities, plan for a alternative operating center and method for exercising and updating the plan.

11. Incorporate in the city or regional emergency response plans a more active participation by the water and sewage iifelines.

In some instances a lifeline agency or its contractors experience difficulty in passing into secured areas, because the agency had not been recognized in advance as an emergency response organization. This could be alleviated by incorporating the agency into the city or regional emergency response organization. 
12. Provide a method, possibly computer based, for logging problems and system operations to estabiish priority for repair activities.

During an emergency many contacts are made to the lifeline agency by telephone, radio, and through the emergency operations center. A system needs to be developed to sort the problems in order to establish a priority for restoration.

13. Conduct a cross training program to include all the lifeline utility personnel in emergency response.

Smaller agencies who have limited personnel should cross train their office personnel in staffing the emergency operations center, telephone switchboard and radio; understanding system operations; and logging operational data (pump, treatment and valve operations); and types of restoration activities (locations, crews, equipment, materials and time to complete the repair). The collection of data is valuable if the agency is eligible for disaster funds.

14. Train personnel in appropriate communication procedures.

Personnel need to be trained in the operation of telephone and radio equipment, to obtain the appropriate information in a mininlum of time, and to dispatch the information to the field working crews to maximize the use of the equipment.

15. Conduct regular periodic emergency response exercises.

The plan needs io be tested by regular and different simulated emergency scenarios, both in-house and on a city or regional basis. One of the most critical parts of the exercise is to test the communication system. The exercises allows the plan to be modified, if necessary.

\section{Provide flexible pipe joints.}

Pipe with flexible joints, such as, rubber gasket, reinforced concrete, vitrified clay, ductile iron, PVC and asbestos cement pipe, performed well in the earthquake; however, it is noted there may be very little of this pipe installed in unstable areas. Cast iron, clay and concrete pipe with rigid caulked joints; corroded steel; and galvanized iron screw pipe especially at the threads experienced most of the damage.

17. Provide fiexible pipe connections to wells, tanks, pumps and other rigid structures.

Tank and well connection piping was damaged during this earthquake because of differential movement. An example of good performance was provided where connecting piping was fitted with double flexible (mechanical) joints.
18. Provide adequate anchorage for air valves and other heavy appurtenances that are installed in an inverted pendulum position.

A few air valves installed on a small pipe in a vertical position broke at the threaded connection.

19. Design for wave action for mechanical appurtenances in treatment plant basin facilities.

Treatment plant mechanical appurtenances need to be designed for wave action (sloshing) caused by earthquakes. In both wastewater and municipal water treatment plants digester and clarifier basins scum troughs, launderers and baffles were damaged, which required the shutdown of the operation.

20. Provide for break away or fusible connections and/or safety cables or chains to prevent malfunctioning mechanical equipment from interfering with other equipment in treatment plant basins.

Differential movement between the mechanical equipment and the reinforced concrete basins placed the mechanical equipment into tension on one side and compression on the other side of the basins. The damaged equipment fell to the bottom of the digester or clarifier and caused a malfunction of the rotating or travelling sludge scraper at the bottom of the basin.

21. Provide for redundancy in the water and sewage system.

Linear water and sewer lines should have redundancy by the use of piping loops, piping grids, muitiple storage and pumping facilities, interconnected pressure zones and alternate power supplies.

22. Install isolation valves and establish a regular valve maintenance program.

Isolation valves are important to isolate the water and sewer lines in unstable ground, poor soil, areas with high potential for a landslide, and at canyon and creek crossings. Reliable operating valves are necessary to minimize the size of areas that must be taken out of service for damage repair.

23. Anchor water quality testing equipment and supply cabinets.

There was no reported damage in water and sewage testing laboratories; however, there was damage in other laboratories due to falling of equipment, falling off of shelves of small chennical storage containers and tipping of supply cabinets. Small chemical containers on open storage shelves should be restrained by a wire, bar or shelf lip from falling off the shelf. Laboratory equipment should be anchored to the bench, shelf or a structural wall. 